\title{
Effects of Biotin Deficiency on Plasma and Tissue Fatty Acid Composition: Evidence for Abnormalities in Rats
}

\author{
DONALD M. MOCK, NELL I. MOCK, SUSAN B. JOHNSON, AND RALPH T. HOLMAN \\ Department of Pediatrics, Divisions of Gastroenterology and Nutrition, University of Iowa, Iowa City, Iowa \\ 52242 [D.M.M., N.I.M.]; and The Hormel Institute, University of Minnesota, Austin, Minnesota [S.B.J., R.T.H.]
}

\begin{abstract}
Abnormalities of fatty acid composition have been detected in the plasma of patients who developed frank biotin deficiency during parenteral nutrition. We sought to determine which abnormalities of fatty acid composition, if any, would be replicated in the biotindeficient rat and to determine the relative temporal relationships of these abnormalities to biotin nutritional status. We measured fatty acid compositions of the phospholipids extracted from plasma, heart, and liver and assessed biotin nutritional status longitudinally in biotin-deficient and biotin-treated rats during progressive biotin deficiency. In the biotin-deficient group, significant increases relative to the biotin-treated group were detected in all three tissues in the odd-chain fatty acids 15:0 and 17:0. In the biotindeficient rats, significant increases in 18:2 $\omega 6$ in liver and $18: 3 \omega 6$ in plasma and liver and significant decreases in 22:5 $\omega 6$ were detected in plasma and liver. The constellation of fatty acid abnormalities observed in the biotin-deficient rats was not identical to that observed in biotin-deficient patients, but abnormalities in composition of odd-chain fatty acids were detected in both human and rat and therefore are attributable to biotin deficiency per se. The abnormalities in fatty acid composition were already present by wk 4 on the egg white diet; the cutaneous findings appeared between wk 3 and 6 . These observations are consistent with the hypothesis that an abnormality in fatty acid metabolism may play a pathogenetic role in the cutaneous manifestations of biotin deficiency. (Pediatr Res 24: 396402, 1988)
\end{abstract}

\section{Abbreviations}

BD, biotin deficient

BT, biotin treated

PL, phospholipid

ANOVA, analysis of variance

PCC, propionyl-CoA carboxylase

MCC, methylcrotonyl-CoA carboxylase

FAME, fatty acid methyl esters

Received March 7, 1988; accepted May 24, 1988.

Correspondence and reprint requests Donald M. Mock, M.D., Ph.D., Department of Pediatrics, Divisions of Gastroenterology and Program in Human Nutrition, University of Iowa Hospitals and Clinics, Iowa City, IA 52242.

Supported by R01 DK36823 and Research Career Development Award K04DK01810 from the Institute of Diabetes and Digestive and Kidney Diseases of the National Institutes of Health.
Several lines of evidence (1-9), including preceding studies from our laboratories $(4,10)$, suggest that biotin deficiency causes abnormalities in fatty acid metabolism that are reflected in abnormalities in tissue fatty acid composition in man and in the rat. In the present study, we sought to determine which of the abnormalities observed in patients who developed biotin deficiency during parenteral nutrition would be replicated in an animal model of biotin deficiency and hence could be attributed to biotin deficiency per se. We also measured the time course of these abnormalities and of several biochemical parameters reflecting biotin nutritional status to determine whether these fatty acid abnormalities are markers for a lesser degree or an earlier stage of biotin deficiency.

\section{METHODS}

Male Sprague-Dawley rats of weanling age (approximately 28 days, 50-70 g) were purchased from Harlan Sprague-Dawley, Inc. (Madison, WI). Rats were housed in hanging wire, stainless steel cages, fed Purina Rodent Laboratory Chow ad libitum (Ralston Purina, St. Louis, MO), and given tap water ad libitum for 6 days until initiation of the experiment. At that time, 38 rats were randomly assigned to one of two treatment groups. The first group (BD) received Teklad diet no. 81079 ad libitum. The diet contained $30 \%$ spray-dried egg white, an amount that had reliably induced biotin deficiency previously as judged by urinary biotin excretion, by plasma concentrations of biotin, and by the appearance of the classical physical findings of biotin deficiency in the rat (11). The second group of rats (BT) were randomly paired to those in the BD group and pair-fed the same diet. The BT group received $250 \mu \mathrm{g}$ of biotin dissolved in $1.25 \mathrm{ml}$ of vehicle ( $0.01 \mathrm{M}$ sodium bicarbonate) by interperitoneal injection twice weekly. The BD group received injections of vehicle only.

Ten pairs of rats (a BD rat and its pair-fed BT rat) were randomly chosen for 24-h urine collections at wk $2,4,6,8$, and 12. The rats were housed in metabolic cages designed to prevent fecal contamination of urine; in the rare instance when gross contamination was noted, the urine sample was discarded. During the 24-h collections, rats were allowed water ad libitum, but food was removed to prevent contamination of the urine with food (particularly with avidin). Studies from our laboratory demonstrate that contamination of urine by this egg white diet reduces the biotin detectable by our ${ }^{125}$ I-avidin binding assay (Mock DM, unpublished data). After completing the urine collections at 4,6 , and $8 \mathrm{wk}$, three pairs of rats were randomly chosen for sacrifice by exsanguination via the abdominal aorta after anesthesia with pentobarbital. At $12 \mathrm{wk}$, all of the remaining rats were killed. After death, the livers and hearts were immediately removed, weighed, frozen in liquid nitrogen, and stored at $-70^{\circ} \mathrm{C}$. Plasma was separated from blood and stored at $-20^{\circ} \mathrm{C}$. 
Portions of the plasma, liver, and heart were shipped on dry ice to the Hormel Institute, Austin, $\mathrm{MN}$ for fatty acid analysis. Three pairs of uncontaminated urine samples at each time point and three pairs of serum samples at wk 12 were randomly selected for measurement of biotin concentration with the ${ }^{125} \mathrm{I}$-avidin assay of Mock and DuBois (12). Hepatic activities of the biotindependent enzymes propionyl-CoA carboxylase (EC 6.4.1.3) and methylcrotonyl-CoA carboxylase (EC 6.4.1.4) were assayed according to the method of Weyler et al. (13).

Fatty acid analysis. Lipids were extracted and the PL fraction was separated by thin-layer chromatography. The PL were converted to methyl esters, and the FAME were analyzed by capillary gas chromatography using methods described previously (10). All results are tabulated as the mean \pm SD of the triplicate values.

\section{STATISTICAL ANALYSIS}

Fatty acid data were analyzed by two-way ANOVA using treatment (BD or BT) as one variable and time on the diet as the other. To confirm the expected increase in odd-chain fatty acids, one-tailed analysis was performed. Two-tailed analysis was used for all other comparisons. An $n$ of 3 at each time point was used for the ANOVA; the data for the three pairs at 12 wk were chosen at random from the larger number of pairs sacrificed. A significant effect of treatment without an accompanying significant interaction between treatment and time was interpreted as evidence of an abnormality that was caused by biotin deficiency but was not becoming significantly more abnormal during the period of the study. A significant interaction of treatment with time was taken as evidence of an abnormality that was caused by biotin deficiency and that progressed with time on the egg white diet. A significant effect of time alone was taken as evidence of a phenomenon not related to biotin deficiency (e.g. maturational effect, dietary change from Chow to egg white diet, etc.).

To compare our findings to a previous publication of Kramer et al. (4), Student's two-tailed paired $t$ tests were performed on fatty acid data of all pairs at wk 12, if suitable samples had been obtained at death. Student's two-tailed paired $t$ tests were also used to test differences in plasma concentrations of biotin. A critical value of $p<0.05$ was chosen as significant for both ANOVA and $t$ testing.

\section{RESULTS}

Evidence of progressive biotin deficiency. The urinary excretion of biotin in the BD group decreased dramatically with time on the egg white diet (Fig. 1). In the BT group, urinary biotin increased with time (Table 1), suggesting that parenteral biotin supplement substantially exceeded that absorbed during the base-
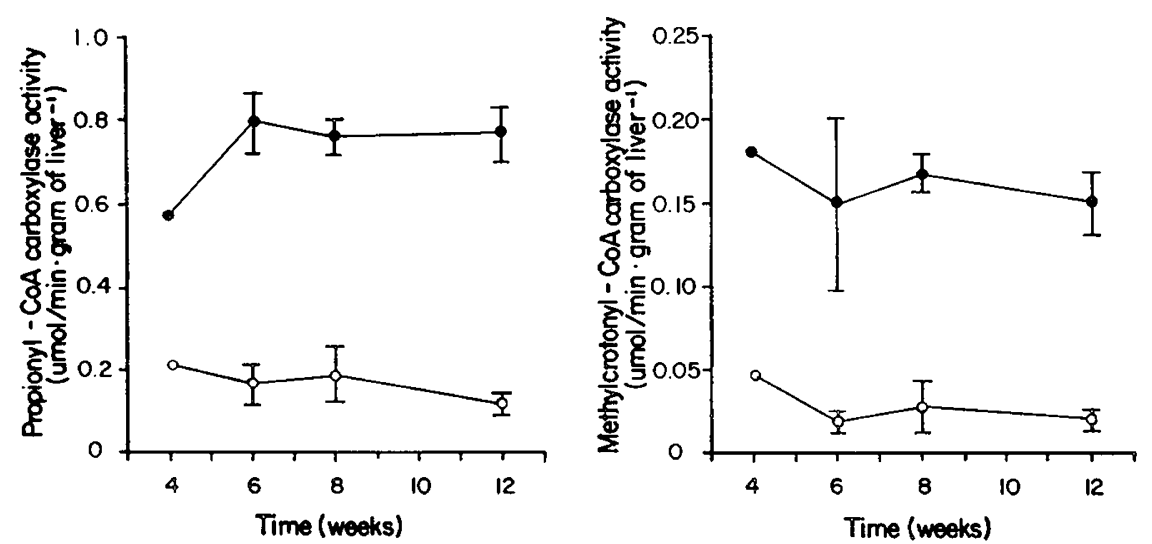

Fig. 2. Effect of biotin deficiency on hepatic propionyl-CoA carboxylase (left) and methylcrotonyl-CoA carboxylase (right) activities. Values for paired $\mathrm{BT}(\odot)$ and $\mathrm{BD}(\mathrm{O})$ rats are depicted as mean $\pm 1 \mathrm{SD}$ for three pairs of rats at wk 6 and 8 and eight pairs at wk 12. At wk 4, data are available from only a single pair of rats.

line period of Chow feeding. The mean plasma concentration of biotin at the termination of the study (wk 12) was significantly less $(p<0.0016)$ in the $\mathrm{BD}$ group $(2.2 \pm 1.5 \mathrm{pmol} / \mathrm{ml}, n=3)$ than in the BT group $(29 \pm 7 \mathrm{pmol} / \mathrm{ml}, n=3)$. After $4 \mathrm{wk}$ on the egg white diet, the mean hepatic activities of two biotindependent carboxylases (PCC and MCC) of the BD group had declined to about $25 \%$ of the mean of the BT group and did not decline further in the subsequent 8 wk (Fig. 2); $p$ values for treatment were $p<0.005$ for both PCC and MCC. No significant effects of time or interaction were detected.By day $16,42 \%$ of

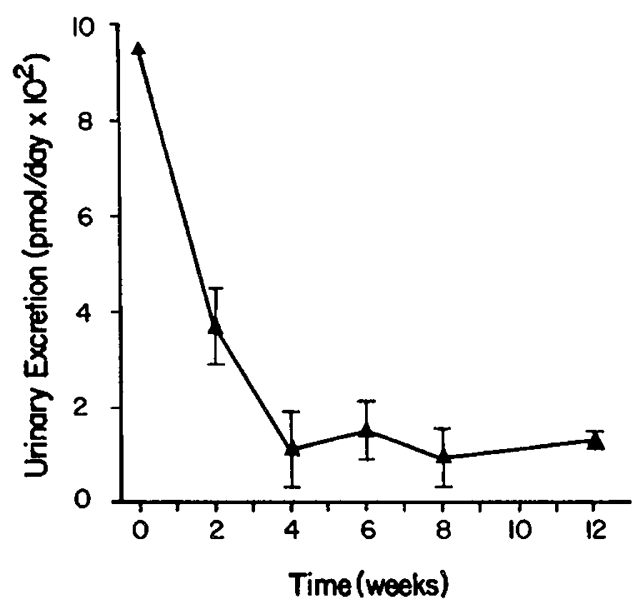

Fig. 1. Decline of urinary excretion of biotin as a function of time on the egg white diet. All points are depicted as mean \pm 1 SD for a group of three rats except at $0 \mathrm{wk}$; the symbol depicts the mean of measurements of samples from two animals.

Table 1. Biotin excreted in urine of treated rats*

\begin{tabular}{ccc}
\hline \multicolumn{3}{c}{ Urinary excretion } \\
\cline { 2 - 3 } Wk & pmol/day $\times 10^{2}$ & $\begin{array}{c}\mathrm{pmol} / \mathrm{mg} \\
\text { creatinine } \times 10^{2}\end{array}$ \\
\hline 0 & 9.44 & 9.64 \\
2 & $78.8 \pm 69.6$ & $72.7 \pm 87.2$ \\
4 & $161 \pm 161$ & $37.8 \pm 7.8$ \\
6 & $181 \pm 47$ & $56.7 \pm 28.8$ \\
8 & $269 \pm 234$ & $43.8 \pm 27.5$ \\
12 & $212 \pm 121$ & $28.8 \pm 1.25$ \\
\hline
\end{tabular}

* Biotin excretion in urine as measured by ${ }^{125} \mathrm{I}$-avidin assay in rats fed a diet containing raw egg white, but receiving twice weekly injections of biotin. All values are mean $\pm \mathrm{SD}$ of $n=3$ except wk 0 which is $n=2$. 

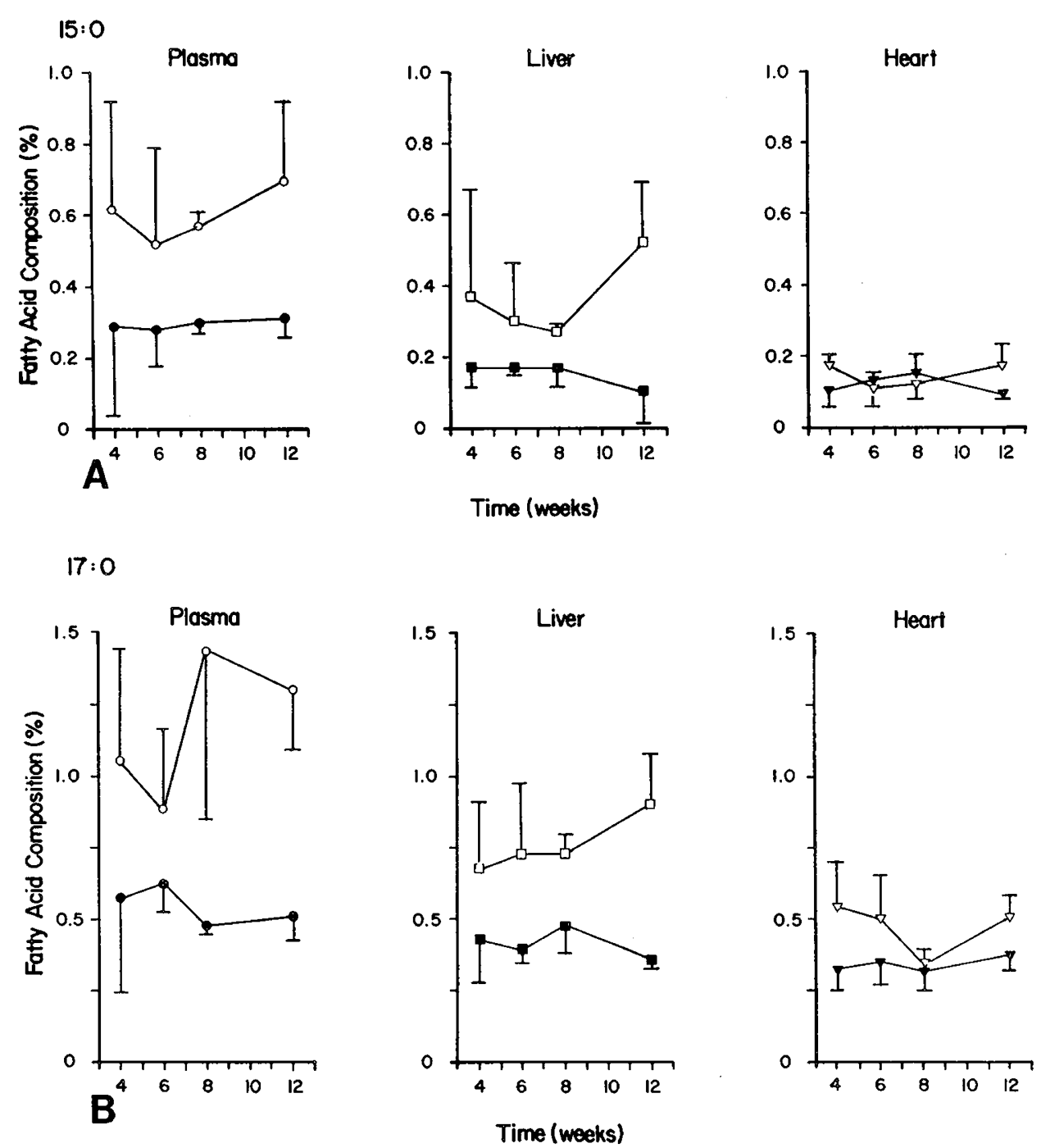

Fig. 3. Effect of biotin deficiency on content of odd-chain fatty acid in plasma, liver, and heart. For $A$ (content of 15:0) and $B$ (content of 17:0), data from BD rats are depicted by open symbols and BT rats by closed symbols. Means \pm 1 SD from three pairs of rats are depicted. Results of analysis of variance are presented in Table 2.

the rats in the BD group were showing early periocular hair loss and mandibular lesions. By the 6 th wk, all rats in the $\mathrm{BD}$ group were showing mandible lesions and loss of large amounts of hair. The ataxia and kangaroo gait were present in the majority of the BD animals by $12 \mathrm{wk}$. In the BT group, no signs of biotin deficiency were present at any time during the study.

Evidence for changes in fatty acid composition. ${ }^{1}$ Odd-chain fatty acids $(15: 0,17: 0)$ in plasma and liver PL were highly significantly increased in the BD group relative to the BT group (Fig. 3; Table 2). The increase was evident at 4 wk and did not change significantly over the next $8 \mathrm{wk}$. In heart PL, 17:0 was significantly increased, and, for 15:0, a significant interaction of treatment with time was detected.

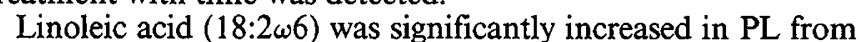
liver but not plasma or heart when the $\mathrm{BD}$ group was compared to the BT group (Fig. $4 A$; Table 3 ). In all three tissues, significant increases with time, independent of treatment effects, were also detected.

The subsequent intermediates in the $\omega 6$ pathway are the product of chain elongation of linoleic acid $(20: 2 \omega 6)$, the product

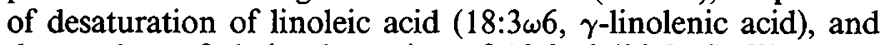

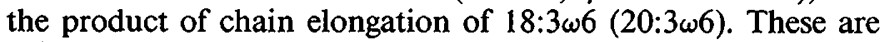
minor components of the total fatty acid profile. Data are pro-

\footnotetext{
${ }^{1}$ Full tabular data for all determinations are in appendix following references.
}

Table 2. Significance of difference between $B D$ and $B T$ rats for odd-chain fatty acids

\begin{tabular}{ccccc}
\hline \multicolumn{2}{c}{ Fatty acid } & Plasma & Liver & Heart \\
\hline \multirow{2}{*}{$15: 0$} & Treatment & $p<0.001$ & $p<0.0025$ & NS \\
& Time & NS & NS & NS \\
& Interaction & NS & NS & $p<0.05$ \\
\multirow{4}{*}{$17: 0$} & Treatment & $p<0.0005$ & $p<0.0005$ & $p<0.005$ \\
& Time & NS & NS & NS \\
& Interaction & NS & NS & NS \\
\hline
\end{tabular}

vided in the appendix tables; results are summarized here. For $20: 2 \omega 6$, a significant interaction of treatment with time was detected in plasma PL $(p<0.05)$. For $18: 3 \omega 6$, both plasma and liver PL showed significant increases in BD compared to BT ( $p<0.01, p<0.05$, respectively). No significant changes in $20: 3 \omega 6$ were detected in any tissue. For arachidonic acid $(20: 4 \omega 6)$, no significant treatment effects were detected. In all three tissues, 22:5 $\omega 6$ (the elongation and desaturation product of $20: 4 \omega 6$ ) tended to decrease in BD compared to BT; significance was reached in plasma and liver (Fig. $4 B$ ). For 22:5 6 in plasma $\mathrm{PL}$, a significant interaction of treatment with time was also detected (Table 3). 


\section{$18: 2 w 6$}

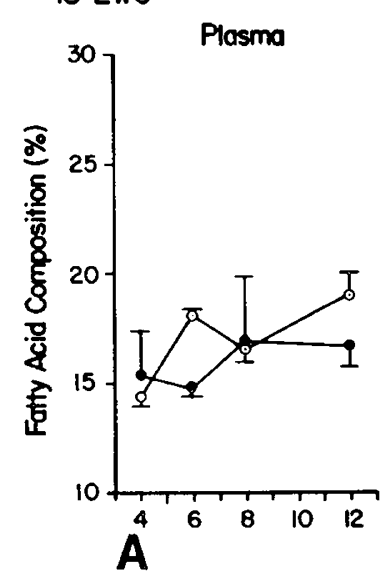

22:5w6

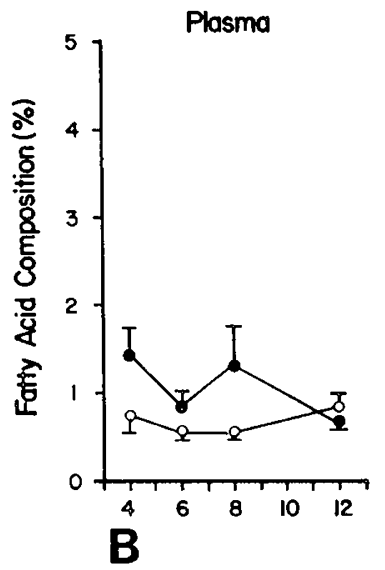

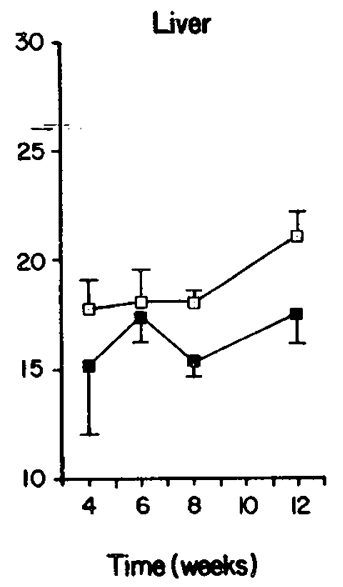

Time (weeks)
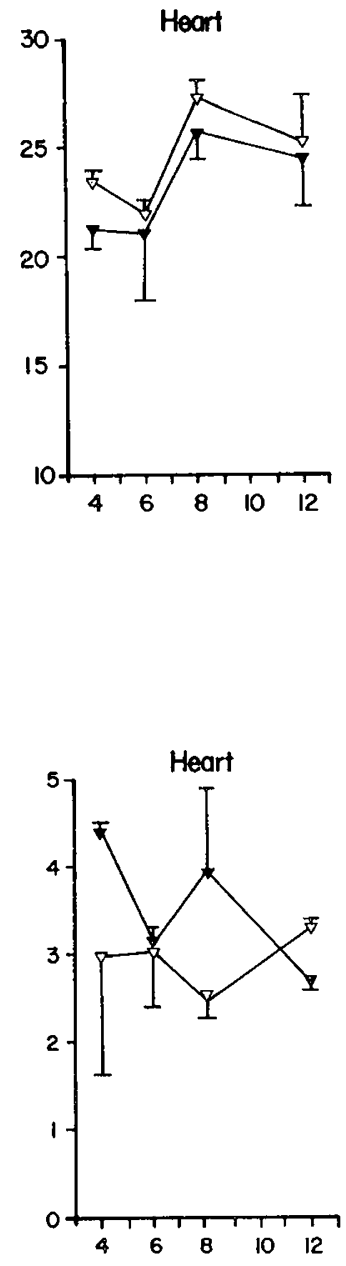

Time (weeks)

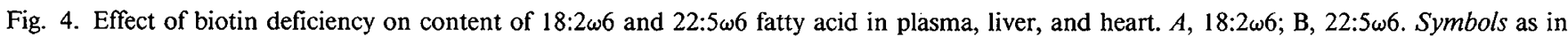
Figure 3. Results of analysis of variance are presented in Table 3.

Four intermediates in the $\omega 3$ family of polyunsaturated fatty acids were measured; these were 18:3 $\omega 3$ (linolenic acid), 20:5 $\omega 3$,

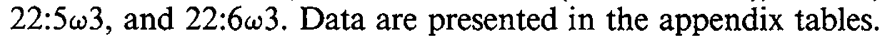
Of these, only $22: 5 \omega 3$ was sigificantly increased in plasma PL of $\mathrm{BD}$ relative to $\mathrm{BT}$ at $p<0.05$. Similarly, a significant interaction of treatment with time for increases of heart PL was found for

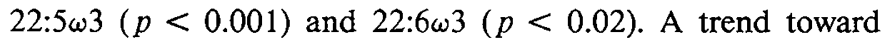
increased content of $18: 3 \omega 3$ in plasma was noted, but significance was not reached.

\section{DISCUSSION}

The data presented here provide evidence that biotin deficiency causes characteristic abnormalities in the fatty acid composition of PL in plasma, liver, and heart. The content of one or both of the two odd-chain fatty acids, 15:0, and 17:0, were significantly increased in all three tissues studied; plasma and liver had the most striking differences. Significant abnormalities were also detected in several of the $\omega 6$ intermediates in PL from plasma and liver. These gross abnormalities of composition could lead to abnormalities in prostaglandin composition or production, particularly if a given lipid subclass (e.g. phosphatidyl choline) is selectively affected. For the $\omega 3$ intermediates measured, biotin deficiency caused an increase in the percentage composition of 22:5 $\omega 3$ in plasma and heart PL, and an increase in heart PL 22:6 33 in the interaction of treatment with time.

In the documented cases of inadvertent biotin deficiency in man, the signs and symptoms of biotin deficiency typically
Table 3. Significance of differences between $B D$ and $B T$ rats for $\omega 6$ fatty acids

\begin{tabular}{clccc}
\hline \multicolumn{2}{c}{ Fatty acid } & Plasma & Liver & Heart \\
\hline \multirow{2}{*}{$18: 2 \mathrm{w} 6$} & Treatment & $\mathrm{NS}$ & $p<0.001$ & $\mathrm{NS}$ \\
& Time & $p<0.05$ & $p<0.01$ & $p<0.001$ \\
& Interaction & $\mathrm{NS}$ & $\mathrm{NS}$ & $\mathrm{NS}$ \\
& & & & \\
$22: 5 \mathrm{w} 6$ & Treatment & $p<0.002$ & $p<0.001$ & $\mathrm{NS}$ \\
& Time & $\mathrm{NS}$ & $p<0.05$ & $p<0.005$ \\
& Interaction & $p<0.02$ & $\mathrm{NS}$ & $\mathrm{NS}$ \\
\hline
\end{tabular}

required months to years to develop (14-21). In studies of biotin deficiency induced experimentally in man and in the rat, the characteristic findings tend to appear after about $6 \mathrm{wk}(1,3-8)$. In our study, the earliest cutaneous manifestations were noted by 4 wk, but were not uniformly and strikingly present until 6 wk. By the 6th wk, the hepatic activities of propionyl-CoA carboxylase and methylcrotonyl-CoA carboxylase of the BD group had decreased to about $25 \%$ of the values for the BT group, and biotin concentrations of plasma and excretion in urine had decreased to 40 and $10 \%$, respectively. We selected 4 , 6,8 , and $12 \mathrm{wk}$ as the time points for analysis of fatty acid composition. Surprisingly, substantial differences in fatty acid composition between the $\mathrm{BD}$ and $\mathrm{BT}$ groups were already present by 4 wk. This finding emphasizes recent observations $(7,22-25)$ 
that abnormalities in fatty acid composition can develop in a matter of a few weeks or less. Thus, the data from this study does not permit us to say when in the first $4 \mathrm{wk}$ the abnormalities appeared. The timing relative to the onset of the cutaneous manifestations of biotin deficiency is consistent with the hypothesis than an abnormality (or abnormalities) in fatty acid metabolism may play a pathogenetic role in the cutaneous disease. Moreover, the early onset of abnormalities in 15:0 and 17:0 suggest that the composition of odd-chain fatty acids deserves further investigation as an early indicator of biotin status at the tissue level.

This study was begun before the publication of similar studies by Kramer et al. (4) and Suchy et al. (6). These two studies detected increases in the composition of odd-chain fatty acid, a finding confirmed in our study.

Our study also expands the information available. In the study of Suchy et al. (6) rats were not pair-fed and fatty acid compositions were determined at a single time point (12-14 wk). The method of fatty acid analysis used by Suchy et al. (6) did not allow evaluation of the polyunsaturated fatty acids but did selectively evaluate saturated acids up to 27:0 Suchy et al. (6) detected significant increases in all serum odd-chain fatty acids from 15:0 to 27:0. The study of Kramer et al. (4) used a pair-fed design and found some abnormalities in fatty acid composition (espe-

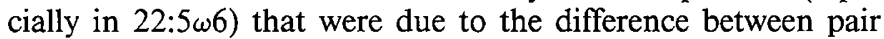
and ad libitum feeding.

Our study also expands the study of Kramer et al. (4) in three important aspects. First, fatty acid composition was analyzed in three tissues (plasma, liver, and heart) rather than liver alone. Thus, comparison to clinical studies is facilitated. Second, serial sampling was done during progressive biotin deficiency rather than at a single time point. Thus, in the analysis of the data, we were able to evaluate differences due to treatment, trends in time not due to biotin deficiency, and interactions of treatment with time. Third, the temporal relationship of the fatty acid abnormalities to biotin nutritional status was assessed by measurement of hepatic carboxylase activities and urinary excretion of biotin.

The current study confirms the findings of Kramer et al. (4) that biotin deficiency causes an increase in the odd-chain fatty acids 15:0 and 17:0 in liver PL. Increases of these fatty acids were also demonstrated in plasma and heart PL in this study suggesting a generalized abnormality in PL composition. The current study also confirms the finding of Kramer et al. (4) that biotin deficiency causes an increase in $18: 2 \omega 6$ in liver PL. A similar change was found in both plasma and heart PL, but only the abnormality in plasma PL reached statistical significance. A significant increase in 18:3 $\omega 6$ of plasma and liver PL was detected in the current study; $18: 3 \omega 6$ data were not reported by Kramer et al. (4). The data of the current study did not confirm the Kramer et al. (4) finding of a significant decrease in $20: 3 \omega 6$ of liver PL, but a trend toward a decrease was apparently present. Our study detected a decrease in 22:5 $\omega 6$ in both plasma and liver that was not found by Kramer et al. (4).

For $\omega 3$ intermediates, Kramer et al. (4) detected significant increases in both $18: 3 \omega 3$ and 22:6 $\omega 3$. Similar trends were seen in the current study although significance was not reached for $18: 3 \omega 3$ in liver, heart, or plasma. A significant increase in plasma

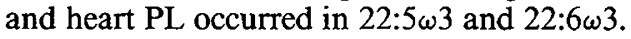

The study reported here and that of Kramer et al. (4) measured the effects of very similar treatments in the same species; yet some disagreements in results occurred. The study of Kramer et al. (4) evaluated fatty acid composition at a single time point ( 7 wk), whereas the current study measured trends in time from 4 to $12 \mathrm{wk}$. To provide a more direct comparison of the two studies, we used Student's paired $t$ test to evaluate the differences in the content of the individual fatty acids from liver PL between pairs of $\mathrm{BD}$ and $\mathrm{BT}$ rats at a single time point (wk 12) in a fashion analogous to that of Kramer et al. (4). We detected significant statistical differences for the same fatty acids identified as significantly different by two-way AnOVA with an exception:
22:5 $\omega 6$ showed no change by $t$ test, but a decrease by ANOVA. In addition, $t$ testing found significant differences in the compar-

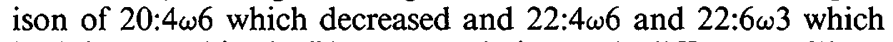
both increased in the BD group relative to the BT group. These results and the direction of change are almost identical with the findings of Kramer et al. (4). In summary, this method of comparison emphasizes the basic agreement between the findings of the two studies.

A previous paper from this laboratory described the abnormalities of fatty acid composition of serum PL, triglyceride, cholesteryl esters, and free fatty acid in three subjects who were profoundly biotin deficient. Abnormal increases in odd-chain fatty acids occurred during biotin deficiency; with biotin supplementation, those abnormalities normalized or decreased toward normal. Our study in rats provides additional evidence that increased content of odd-chain fatty acids is the result of biotin deficiency per se.

In serum PL of the three patients with biotin deficiency,

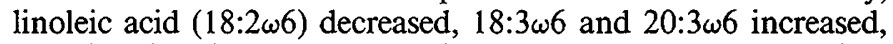
arachidonic acid $(20: 4 \omega 6)$ remained normal, and $22: 4 \omega 6$ varied, with one patient having decreased amounts and two patients having increased amounts. Biotin treatment did not result in a consistent resolution in any of these abnormalities. In the current animal study, biotin deficiency significantly increased both lin-

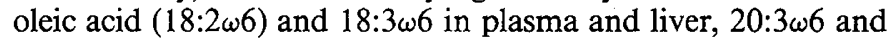
$20: 4 \omega 6$ did not change significantly in any tissue, and 22:5 6 , the chain elongation and desaturation product of arachidonic acid, decreased significantly in plasma and liver PL of BD rats. Thus the $\omega 6$ abnormalities of the patients were not generally found in this animal study; indeed, for some intermediates, opposite effects were seen. Based on a comparison of the human and the rat studies, we are not able to determine if the differences in abnormalities in the $\omega 6$ series are attributable to species differences or to other factors such as the differences in composition and/or route of administration of lipids or other nutrients.

The data presented here do not address the question of whether the fatty acid abnormalities have an etiologic role in any of the physical findings of biotin deficiency. The evidence is accumulating that essential fatty acid deficiency causes a scaly dermatitis and alopecia by affecting prostaglandin metabolism (26-29). One is tempted to speculate that the gross compositional abnormalities of $\omega 6$ fatty acids observed in this study might lead to abnormalities in prostaglandin composition and might in turn cause the cutaneous manifestations of biotin deficiency. Our ongoing studies of the effect of essential fatty acid on the cutaneous manifestations provide evidence for such a functional role (30).

\section{REFERENCES}

1. Puddu P, Zanetti P, Turchetto E, Marchetti M 1967 Aspects of liver lipid metabolism in the biotin-deficient rat. J Nutr 91:509-513

2. Dakshinamurti K, Desjardins PR 1968 Lipogenesis in biotin deficiency. Can J Biochem 46:1261-1267

3. Travis S, Mathias MM, Dupont J 1972 Effect of biotin deficiency on the catabolism of linoleate in the rat. J Nutr 102:767-772

4. Kramer TR, Briske-Anderson M, Johnson SB, Holman RT 1984 Effects of biotin deficiency on polyunsaturated fatty acid metabolism in rats. $\mathrm{J}$ Nutr 114:2047-2052

5. Marshall MW, Ziyad J 1985 Effects of biotin and fat type on blood lipids, red cell and liver fatty acids of rats. In: Dakshinamurti K, Bhagavan HN (eds) Biotin. Ann NY Acad Sci 447:407-413

6. Suchy SF, Rizzo WB, Wolf B 1986 Effect of biotin deficiency and supplementation on lipid metabolism in rats: saturated fatty acids. Am $\mathrm{J}$ Clin Nutr 44:475-480

7. Marshall MW, Kliman PG, Washington VA 1980 Effects of biotin on lipids and other constituents of plasma of healthy men and women. Artery 7:330351

8. Marshall MW, Judd JT, Baker H 1985 Effects of low and high fat diets varying in ratio of polyunsaturated to saturated fatty acids on biotin intakes and biotin in serum, red cells and urine of adult men. Nutr Res 5:801-814

9. Gonzalez-Rios MDC, Whitney SC, Williams ML, Elias PM, Packman S 1985 Lipid metabolism in biotin-responsive multiple carboxylase deficiency. $J$ Inherited Metab Dis 8:184-186

10. Mock DM, Johnson SB, Holman RT 1988 Effects of biotin deficiency on 
serum fatty acid composition: Evidence for abnormalities in humans. $\mathrm{J}$ Nutr 118:342-348

11. Whitehead CC 1978 Effect of nutrient deficiencies in animals: biotin, In: Recheigl M (ed). CRC Handbook Series in Nutrition and Food, 2, Section E. CRC Press, West Palm Beach, FL

12. Mock DM, DuBois D 1986 A sequential, solid phase assay for biotin in physiologic fluids that correlates with expected biotin status. Anal Biochem 153:272-278

13. Weyler W, Sweetman L, Maggio DC, Nyhan WL 1977 Deficiency of propionylCoA carboxylase and methylcrotonyl-CoA carboxylase in a patient with methylcrotonylglycinuria. Clin Chim Acta 76:321-328

14. Mock DM, Delorimer AA, Liebman WM, Sweetman L, Baker H 1981 Biotin deficiency: an unusual complication of parenteral alimentation. $\mathrm{N}$ Engl J Med 304:820-823

15. Sydenstricker VP, Singal SA, Briggs AP, DeVaughn NM, Isbell H 1942 Observations on the "egg white injury" in man. JAMA 118:1199-1200

16. Scott D 1958 Clinical biotin deficiency ("egg white injury"): report of a case with some remarks on serum cholesterol. Acta Med Scand 162:69-70

17. Baugh CM, Malone HJ, Butterworth CE Jr 1968 Human biotin deficiency: a case history of biotin deficiency induced by raw egg consumption in a cirrhotic patient. Am J Clin Nutr 21:173-182

18. Sweetman L, Surh L, Baker H, Peterson RM, Nyhan WL 1981 Clinical and metabolic abnormalities in a boy with dietary deficiency of biotin. Pediatrics 68:553

19. McClain CJ, Baker H, Onstad GR 1982 Biotin deficiency in an adult during home parenteral nutrition. JAMA 247:3116-3117

20. Gillis J, Murphy FR, Boxall LBH, Pencharz PB 1982 Biotin deficiency in child on long-term TPN. JPEN 6:308-310
21. Kien CL, Kohler E, Goodman SI, Berlow S, Hong R, Horowitz SP, Baker H 1981 Biotin-responsive in vivo carboxylase deficiency in two siblings with secretory diarrhea receiving total parenteral nutrition. J Pediatr 99:546-550

22. CaldwelI MD Jonsson HT Othersen HA Jr 1972 Essential fatty acid deficiency in an infant receiving prolonged parenteral alimentation. J Pediatr 81:894898

23. White HB, Turner MD, Turner AC, Miller RC 1973 Blood lipid alterations in infants receiving intravenous fat-free alimentation. J Pediatr 83:305

24. Paulsrud JR, Pennsler RL, Whittier CE, Stewart A, Holman RT 1972 Essential fatty acid deficiency in infants induced by fat-free intravenous feeding. Am J Clin Nutr 25:897

25. Holman RT 1978 Essential fatty acid deficiency. Symposium on Total Parenteral Nutrition. American Medical Association, Nashville, TN, pp 214-220

26. Ziboh VA, Hsia SL 1972 Effects of prostaglandin $E_{2}$ on rat skin: inhibition of sterol ester biosynthesis and clearing of scaly lesions in essential fatty acid deficiency. J Lipid Res 13:458-467

27. Hartop PJ, Prottey C 1972 Changes in transepidermal water loss and the composition of epidermal lecithin after application of pure fatty acid triglycerides to the skin of essential fatty acid-deficient rats. Br J Lipid Res 13:458467

28. Hansen HS 1981 Essential fatty acid supplemented diet increases renal excretion of prostaglandin $E_{2}$ and water in essential fatty acid deficient rats. Lipids 16:849-854

29. Hansen HS 1982 Essential fatty acid-supplemented diet decreases renal excretion of immunoreactive arginine-vasopressin in essential fatty acid deficient rats. Lipids 17:321-322

30. Mock DM 1988 Evidence for a pathogenic role of fatty acid (FA) abnormalities in the cutaneous manifestations of biotin deficiency. FASEB J 2:A 1204 
Appendix Table 1.

Composition of $\omega 6$ fatty acids*

\begin{tabular}{|c|c|c|c|c|c|c|c|}
\hline \multirow[b]{2}{*}{ Fatty acid } & \multirow[b]{2}{*}{ Time } & \multicolumn{2}{|c|}{ Plasma } & \multicolumn{2}{|c|}{ Liver } & \multicolumn{2}{|c|}{ Heart } \\
\hline & & $\mathrm{BD}$ & BT & $\mathrm{BD}$ & $\mathrm{BT}$ & $\mathrm{BD}$ & BT \\
\hline $18: 2 \omega 6$ & $4 \mathrm{wk}$ & $14.50 \pm 0.21$ & $15.35 \pm 1.89$ & $17.38 \pm 1.51$ & $15.32 \pm 2.27$ & $23.27 \pm 0.34$ & $21.45 \pm 0.77$ \\
\hline (linoleic & $6 \mathrm{wk}$ & $17.96 \pm 0.01$ & $14.76 \pm 0.35$ & $17.91 \pm 1.02$ & $17.50 \pm 0.95$ & $22.11 \pm 0.34$ & $21.39 \pm 3.07$ \\
\hline \multirow[t]{6}{*}{ acid) } & $8 w k$ & $16.42 \pm 0.41$ & $16.59 \pm 2.90$ & $17.92 \pm 0.29$ & $15.55 \pm 0.61$ & $27.14 \pm 0.86$ & $25.84 \pm 1.13$ \\
\hline & $12 \mathrm{wk}$ & $18.89 \pm 1.02$ & $16.33 \pm 0.52$ & $21.12 \pm 0.89$ & $17.42 \pm 0.75$ & $25.13 \pm 2.40$ & $24.39 \pm 1.53$ \\
\hline & & Two-way ANO & results & & & & \\
\hline & Treatment & $0.1<p>0.05$ & & $p<0.001$ & & NS & \\
\hline & Time & $p<0.05$ & & $p<0.01$ & & $p<0.001$ & \\
\hline & Interaction & NS & & NS & & NS & \\
\hline \multirow[t]{8}{*}{$20: 2 \omega 6$} & $4 \mathrm{wk}$ & $0.37 \pm 0.16$ & $0.48 \pm 0.42$ & $0.47 \pm 0.16$ & $0.45 \pm 0.05$ & $0.30 \pm 0.04$ & $0.33 \pm 0.02$ \\
\hline & $6 \mathrm{wk}$ & $0.29 \pm 0.03$ & $0.31 \pm 0.03$ & $0.35 \pm 0.07$ & $0.36 \pm 0.08$ & $0.39 \pm 0.11$ & $0.38 \pm 0.16$ \\
\hline & $8 \mathrm{wk}$ & $0.37 \pm 0.01$ & $0.32 \pm 0.09$ & $0.32 \pm 0.05$ & $0.33 \pm 0.01$ & $0.17 \pm 0.02$ & $0.21 \pm 0.04$ \\
\hline & $12 \mathrm{wk}$ & $0.47 \pm 0.11$ & $0.15 \pm 0.01$ & $0.39 \pm 0.04$ & $0.49 \pm 0.34$ & $0.27 \pm 0.12$ & $0.17 \pm 0.02$ \\
\hline & & Two-way ANO & results & & & & \\
\hline & Treatment & NS & & NS & & NS & \\
\hline & Time & NS & & NS & & $p<0.01$ & \\
\hline & Interaction & $p<0.05$ & & NS & & NS & \\
\hline \multirow[t]{8}{*}{$18: 3 \omega 6$} & $4 \mathrm{wk}$ & $0.26 \pm 0.03$ & $0.16 \pm 0.05$ & $0.29 \pm 0.07$ & $0.23 \pm 0.02$ & $0.18 \pm 0.03$ & $0.13 \pm 0.01$ \\
\hline & $6 \mathrm{wk}$ & $0.17 \pm 0.01$ & $0.12 \pm 0.11$ & $0.31 \pm 0.04$ & $0.27 \pm 0.09$ & $0.17 \pm 0.02$ & $0.13 \pm 0.02$ \\
\hline & $8 \mathrm{wk}$ & $0.16 \pm 0.03$ & $0.12 \pm 0.10$ & $0.39 \pm 0.09$ & $0.17 \pm 0.03$ & $0.10 \pm 0.02$ & $0.16 \pm 0.05$ \\
\hline & $12 \mathrm{wk}$ & $0.24 \pm 0.05$ & $0.12 \pm 0.11$ & $0.53 \pm 0.18$ & $0.33 \pm 0.13$ & $0.12 \pm 0.11$ & $0.10 \pm 0.02$ \\
\hline & & Two-way ANO & results & & & & \\
\hline & Treatment & $p<0.01$ & & $p<0.05$ & & NS & \\
\hline & Time & NS & & NS & & NS & \\
\hline & Interaction & NS & & NS & & NS & \\
\hline \multirow[t]{8}{*}{$20: 3 \omega 6$} & $4 \mathrm{wk}$ & $0.51 \pm 0.24$ & $0.60 \pm 0.28$ & $0.28 \pm 0.06$ & $0.39 \pm 0.14$ & $0.29 \pm 0.07$ & $0.34 \pm 0.08$ \\
\hline & $6 \mathrm{wk}$ & $0.41 \pm 0.18$ & $0.39 \pm 0.04$ & $0.29 \pm 0.05$ & $0.33 \pm 0.10$ & $0.33 \pm 0.02$ & $0.32 \pm 0.02$ \\
\hline & $8 \mathrm{wk}$ & $0.38 \pm 0.03$ & $0.41 \pm 0.17$ & $0.31 \pm 0.02$ & $0.31 \pm 0.03$ & $0.28 \pm 0.01$ & $0.30 \pm 0.06$ \\
\hline & $12 \mathrm{wk}$ & $0.32 \pm 0.03$ & $0.40 \pm 0.12$ & $0.28 \pm 0.11$ & $0.31 \pm 0.02$ & $0.25 \pm 0.05$ & $0.27 \pm 0.02$ \\
\hline & & Two-way ANO & results & & & & \\
\hline & Treatment & NS & & NS & & NS & \\
\hline & Time & NS & & NS & & NS & \\
\hline & Interaction & NS & & NS & & NS & \\
\hline \multirow{8}{*}{$\begin{array}{l}20: 4 \omega 6 \\
\quad \text { (arachidonic } \\
\text { acid) }\end{array}$} & $4 \mathrm{wk}$ & $22.03 \pm 1.25$ & $27.53 \pm 7.18$ & $35.43 \pm 4.14$ & $31.57 \pm 1.66$ & $26.36 \pm 4.11$ & $26.27 \pm 1.37$ \\
\hline & $6 \mathrm{wk}$ & $22.97 \pm 0.51$ & $21.38 \pm 1.14$ & $32.38 \pm 2.81$ & $33.63 \pm 4.18$ & $26.94 \pm 3.13$ & $26.94 \pm 4.18$ \\
\hline & $8 \mathrm{wk}$ & $19.47 \pm 1.01$ & $21.77 \pm 3.76$ & $30.12 \pm 0.13$ & $30.71 \pm 3.03$ & $27.94 \pm 2.29$ & $29.11 \pm 2.13$ \\
\hline & $12 \mathrm{wk}$ & $15.39 \pm 0.90$ & $17.22 \pm 4.53$ & $29.94 \pm 3.20$ & $33.33 \pm 1.98$ & $24.90 \pm 3.20$ & $26.92 \pm 2.04$ \\
\hline & & Two-way ANO & results & & & & \\
\hline & Treatment & NS & & NS & & NS & \\
\hline & Time & $p<0.01$ & & NS & & NS & \\
\hline & Interaction & NS & & NS & & NS & \\
\hline \multirow[t]{8}{*}{$22: 4 \omega 6$} & $4 \mathrm{wk}$ & $0.72 \pm 0.10$ & $0.94 \pm 0.22$ & $0.59 \pm 0.10$ & $0.85 \pm 0.01$ & $1.72 \pm 0.42$ & $2.11 \pm 0.07$ \\
\hline & $6 \mathrm{wk}$ & $0.55 \pm 0.01$ & $0.84 \pm 0.14$ & $0.75 \pm 0.35$ & $0.72 \pm 0.17$ & $1.78 \pm 0.41$ & $2.23 \pm 0.18$ \\
\hline & $8 \mathrm{wk}$ & $0.60 \pm 0.01$ & $0.78 \pm 0.35$ & $0.62 \pm 0.03$ & $0.82 \pm 0.09$ & $1.46 \pm 0.02$ & $1.60 \pm 0.18$ \\
\hline & $12 \mathrm{wk}$ & $0.74 \pm 0.07$ & $0.60 \pm 0.20$ & $0.74 \pm 0.10$ & $0.73 \pm 0.10$ & $1.56 \pm 0.13$ & $1.31 \pm 0.07$ \\
\hline & & Two-way ANO & results & & & & \\
\hline & Treatment & NS & & NS & & NS & \\
\hline & Time & NS & & NS & & $p<0.005$ & \\
\hline & Interaction & NS & & NS & & NS & \\
\hline \multirow[t]{8}{*}{$22: 5 \omega 6$} & $4 \mathrm{wk}$ & $0.73 \pm 0.18$ & $1.45 \pm 0.28$ & $0.99 \pm 0.31$ & $2.00 \pm 0.39$ & $2.99 \pm 1.32$ & $4.46 \pm 0.10$ \\
\hline & $6 \mathrm{wk}$ & $0.55 \pm 0.09$ & $0.84 \pm 0.14$ & $0.69 \pm 0.27$ & $1.32 \pm 0.24$ & $3.03 \pm 0.63$ & $3.11 \pm 0.14$ \\
\hline & $8 \mathrm{wk}$ & $0.56 \pm 0.01$ & $1.31 \pm 0.46$ & $0.79 \pm 0.04$ & $1.65 \pm 0.14$ & $2.50 \pm 0.21$ & $3.96 \pm 0.93$ \\
\hline & $12 \mathrm{wk}$ & $0.86 \pm 0.06$ & $0.67 \pm 0.26$ & $1.01 \pm 0.04$ & $1.41 \pm 0.22$ & $3.32 \pm 0.09$ & $2.70 \pm 0.07$ \\
\hline & & Two-way ANO & Results & & & & \\
\hline & Treatment & $p<0.002$ & & $p<0.001$ & & NS & \\
\hline & Time & NS & & $p<0.05$ & & $p<0.005$ & \\
\hline & Interaction & $p<0.02$ & & NS & & NS & \\
\hline
\end{tabular}

* Data for the composition of $\omega 6$ fatty acids are tabulated as mean \pm SD. Significance from two-way ANOVA is expressed as $p$ values for treatment, time, and interaction of treatment with time. 
Appendix Table 2.

Composition of $\omega 3$ fatty acids*

\begin{tabular}{|c|c|c|c|c|c|c|c|}
\hline \multirow[b]{2}{*}{ Fatty acid } & \multirow[b]{2}{*}{ Time } & \multicolumn{2}{|c|}{ Plasma } & \multicolumn{2}{|c|}{ Liver } & \multicolumn{2}{|c|}{ Heart } \\
\hline & & $\mathrm{BD}$ & $\mathrm{BT}$ & $\mathrm{BD}$ & BT & $\mathrm{BD}$ & BT \\
\hline $18: 3 \omega 3$ & $4 \mathrm{wk}$ & $0.04 \pm 0.06$ & $0 \pm 0$ & $0.05 \pm 0.03$ & $0.02 \pm 0.02$ & $0.08 \pm 0.02$ & $0.18 \pm 0.17$ \\
\hline (lino- & $6 \mathrm{wk}$ & $0 \pm 0$ & $0 \pm 0$ & $0.05 \pm 0$ & $0.05 \pm 0.05$ & $0.04 \pm 0.05$ & $0.03 \pm 0.05$ \\
\hline lenic) & $8 \mathrm{wk}$ & $0 \pm 0$ & $0 \pm 0$ & $0.03 \pm 0.03$ & $0.02 \pm 0.02$ & $0.09 \pm 0.03$ & $0.07 \pm 0.02$ \\
\hline \multirow[t]{5}{*}{ acid) } & $12 \mathrm{wk}$ & $0.11 \pm 0.13$ & $0.02 \pm 0.04$ & $0.05 \pm 0.06$ & $0.03 \pm 0.03$ & $0.05 \pm 0.08$ & $0.05 \pm 0.05$ \\
\hline & & Two-way ANO & results & & & & \\
\hline & Treatment & NS & & NS & & NS & \\
\hline & Time & NS & & NS & & NS & \\
\hline & Interaction & NS & & NS & & NS & \\
\hline \multirow[t]{8}{*}{$20: 5 \omega 3$} & $4 \mathrm{wk}$ & $0.02 \pm 0.00$ & $0.43 \pm 0.46$ & $0.05 \pm 0.02$ & $0.04 \pm 0.01$ & $0.10 \pm 0.05$ & $0.02 \pm 0.02$ \\
\hline & $6 \mathrm{wk}$ & $0.02 \pm 0.00$ & $0.02 \pm 0.00$ & $0.04 \pm 0.04$ & $0.12 \pm 0.11$ & $0.11 \pm 0.18$ & $0.24 \pm 0.30$ \\
\hline & $8 \mathrm{wk}$ & $0.03 \pm 0.01$ & $0.04 \pm 0.02$ & $0.49 \pm 0.49$ & $0.07 \pm 0.02$ & $0.07 \pm 0.01$ & $0.04 \pm 0.04$ \\
\hline & $12 \mathrm{wk}$ & $0.02 \pm 0.00$ & $0.64 \pm 1.09$ & $0.18 \pm 0.25$ & $0.27 \pm 0.37$ & $0.03 \pm 0.05$ & $0.02 \pm 0.02$ \\
\hline & & Two-way ANO & results & & & & \\
\hline & Treatment & NS & & NS & & NS & \\
\hline & Time & NS & & NS & & NS & \\
\hline & Interaction & NS & & NS & & NS & \\
\hline \multirow[t]{8}{*}{$22: 5 \omega 3$} & 4 wk & $0.37 \pm 0.11$ & $0.35 \pm 0.30$ & $0.75 \pm 0.44$ & $0.51 \pm 0.04$ & $1.48 \pm 1.01$ & $0.87 \pm 0.06$ \\
\hline & $6 \mathrm{wk}$ & $0.38 \pm 0.04$ & $0.24 \pm 0.19$ & $0.54 \pm 0.09$ & $0.50 \pm 0.06$ & $1.02 \pm 0.21$ & $0.96 \pm 0.11$ \\
\hline & $8 \mathrm{wk}$ & $0.34 \pm 0.08$ & $0.29 \pm 0.05$ & $0.55 \pm 0.11$ & $0.48 \pm 0.01$ & $1.10 \pm 0.04$ & $4.21 \pm 0.82$ \\
\hline & $12 \mathrm{wk}$ & $0.60 \pm 0.15$ & $0.27 \pm 0.23$ & $0.69 \pm 0.06$ & $0.56 \pm 0.05$ & $1.29 \pm 0.02$ & $0.85 \pm 0.20$ \\
\hline & & Two-way ANO & results & & & & \\
\hline & Treatment & $p<0.05$ & & NS & & NS & \\
\hline & Time & NS & & NS & & $p<0.001$ & \\
\hline & Interaction & NS & & NS & & $p<0.001$ & \\
\hline \multirow[t]{8}{*}{$22: 6 \omega 3$} & 4 wk & $2.95 \pm 0.32$ & $2.71 \pm 0.05$ & $5.48 \pm 0.53$ & $5.50 \pm 1.65$ & $5.11 \pm 0.92$ & $7.15 \pm 2.51$ \\
\hline & $6 \mathrm{wk}$ & $2.67 \pm 0.12$ & $2.27 \pm 0.32$ & $5.02 \pm 0.21$ & $6.13 \pm 0.62$ & $5.87 \pm 1.5$ & $5.83 \pm 2.34$ \\
\hline & 8 wk & $2.39 \pm 0.26$ & $2.58 \pm 0.43$ & $4.79 \pm 0.19$ & $4.52 \pm 0.58$ & $6.32 \pm 0.83$ & $5.24 \pm 1.31$ \\
\hline & $12 \mathrm{wk}$ & $3.80 \pm 1.04$ & $1.96 \pm 1.38$ & $6.46 \pm 0.85$ & $5.15 \pm 0.21$ & $8.84 \pm 0.79$ & $3.80 \pm 0.69$ \\
\hline & & Two-way ANO & results & & & & \\
\hline & Treatment & $0.1<p>0.05$ & & NS & & NS & \\
\hline & Time & NS & $\therefore$ & NS & & NS & \\
\hline & Interaction & NS & & NS & & $p<0.02$ & \\
\hline
\end{tabular}

* Data for the composition of the $\omega 3$ fatty acids are tabulated at mean \pm SD. Significance from two-way ANOVA is expressed as $p$ values for treatment, time, and interaction of treatment with time. Zero values indicate fatty acid was less than the limit of detectability at $0.1 \%$.

Appendix Table 3.

Composition of $\omega 9$ fatty acids*

\begin{tabular}{|c|c|c|c|c|c|c|c|}
\hline \multirow[b]{2}{*}{ Fatty acid } & \multirow[b]{2}{*}{ Time } & \multicolumn{2}{|c|}{ Plasma } & \multicolumn{2}{|c|}{ Liver } & \multicolumn{2}{|c|}{ Heart } \\
\hline & & $\mathrm{BD}$ & BT & $\mathrm{BD}$ & BT & $\mathrm{BD}$ & BT \\
\hline \multirow[t]{8}{*}{$18: 1 \omega 9$} & $4 \mathrm{wk}$ & $4.29 \pm 0.27$ & $4.06 \pm 0.76$ & $3.10 \pm 0.43$ & $2.85 \pm 0.26$ & $3.01 \pm 0.25$ & $3.10 \pm 0.25$ \\
\hline & $6 \mathrm{wk}$ & $4.30 \pm 0.13$ & $3.74 \pm 0.18$ & $3.59 \pm 0.11$ & $2.79 \pm 0.30$ & $3.73 \pm 0.43$ & $3.36 \pm 0.39$ \\
\hline & $8 \mathrm{wk}$ & $4.67 \pm 0.37$ & $3.75 \pm 0.10$ & $3.73 \pm 0.37$ & $13.11 \pm 17.32$ & $3.36 \pm 0.39$ & $2.99 \pm 0.33$ \\
\hline & $12 \mathrm{wk}$ & $5.07 \pm 0.11$ & $4.93 \pm 0.67$ & $3.46 \pm 0.14$ & $3.05 \pm 0.21$ & $3.01 \pm 0.33$ & $3.22 \pm 0.37$ \\
\hline & & Two-way AN & A results & & & & \\
\hline & Treatment & NS & & NS & & NS & \\
\hline & Time & NS & & NS & & NS & \\
\hline & Interaction & NS & & NS & & NS & \\
\hline \multirow[t]{8}{*}{$20: 3 \omega 9$} & $4 \mathrm{wk}$ & $0.00 \pm 0.00$ & $0.00 \pm 0.00$ & $0.00 \pm 0.00$ & $0.00 \pm 0.00$ & $0.00 \pm 0.00$ & $0.00 \pm 0.00$ \\
\hline & $6 \mathrm{wk}$ & $0.00 \pm 0.00$ & $0.06 \pm 0.10$ & $0.00 \pm 0.00$ & $0.00 \pm 0.00$ & $0.00 \pm 0.00$ & $0.13 \pm 0.23$ \\
\hline & $8 \mathrm{wk}$ & $0.00 \pm 0.00$ & $0.00 \pm 0.00$ & $0.00 \pm 0.00$ & $0.00 \pm 0.00$ & $0.00 \pm 0.00$ & $0.00 \pm 0.00$ \\
\hline & $12 \mathrm{wk}$ & $0.00 \pm 0.00$ & $0.05 \pm 0.10$ & $0.00 \pm 0.00$ & $0.00 \pm 0.00$ & $0.00 \pm 0.00$ & $0.00 \pm 0.00$ \\
\hline & & Two-way AN & A results & & & & \\
\hline & Treatment & NS & & NS & & NS & \\
\hline & Time & NS & & NS & & NS & \\
\hline & Interaction & NS & & NS & & NS & \\
\hline
\end{tabular}

* Data for the composition of the $\omega 9$ fatty acids are tabulated as mean \pm SD. Significance from two-way ANOVA is expressed as $p$ values for treatment, time, and interaction of treatment with time. Zero values indicate fatty acid was less than the limit of detectability at $0.01 \%$. 